\title{
Studies enhancement of transient stability by single machine infinite bus system and setting purpose genetic algorithm
}

\author{
Zinah S. Hasan', Dalya H. Al-Mamoori² \\ ${ }^{1}$ Babylon Technical Institute, Al-Furat Al-Awsat Technical University, Najaf, Iraq \\ ${ }^{2}$ Department of Electrical Power Engineering, Technical College Al-Mussaib, Al-Furat Al- Awsat Technical University, Babil, Iraq
}

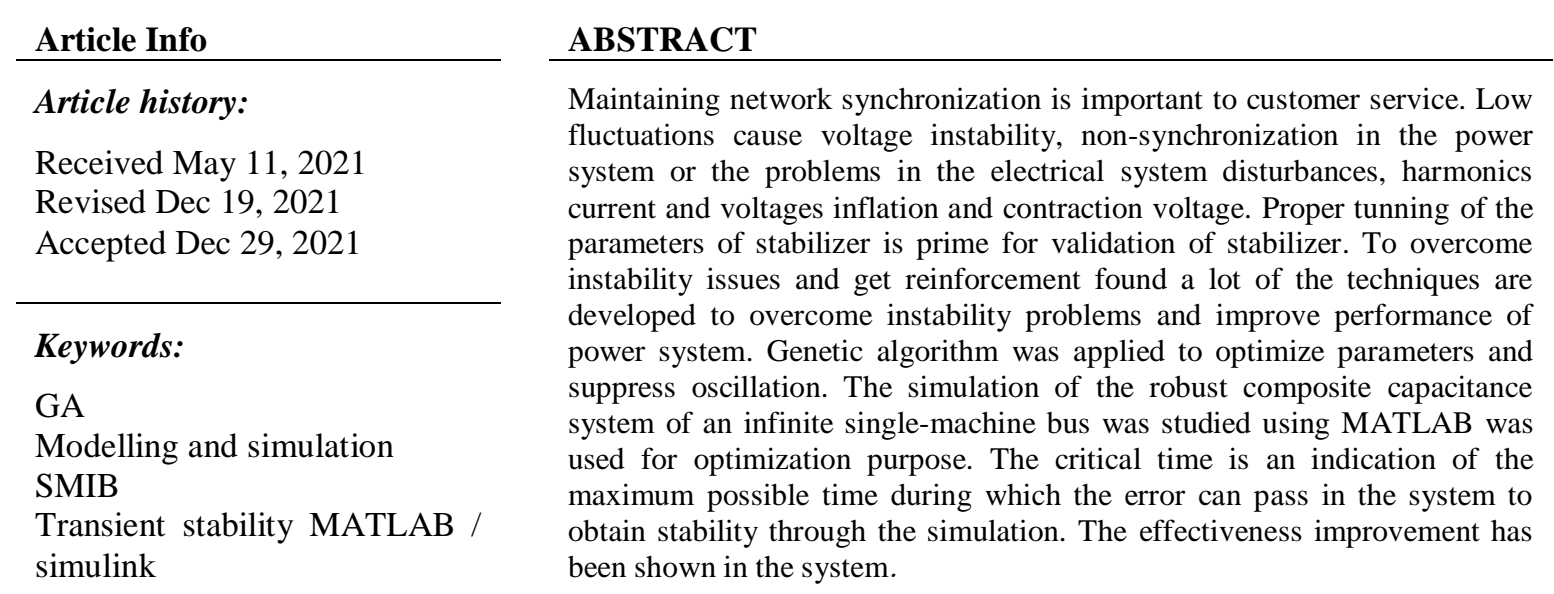

This is an open access article under the CC BY-SA license.

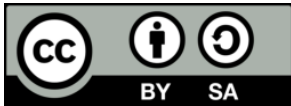

\section{Corresponding Author:}

Dalya H. Al-Mamoori

Department of Electrical Power Engineering, Technical College Al-Mussaib

Al-Furat Al- Awsat Technical University, Babil, Iraq

Email: daliahamza784@atu.edu.iq

\section{INTRODUCTION}

The modernity of the power system is that it consists of a complex network that contains many buses and generators that are highly interconnected. The need for electricity has led to an improvement in the generation of the network instead of building new lines, and that the flow of energy in transmission lines has become a problem of transient stability when a fault occurs. Synchronicity is affected by the great and the small perforations [1]. Stability is one of the necessary characteristics in the system and is divided into small signal stability and transient stability [2], [3]. To optimally allocate photovoltaic power based on distributed generations (PV-DG) the proposed hybrid particle swarm (PSO) has been applied to 33-bus and 69-bus [4]-[6]. In order to obtain high accuracy and mend stability margins, optimized positioned phasor measuring unit (PMU) were combined in a wide area measurement system (WAMS) and increased the conventional L index on 9-bus and 14-bus networks [7]. Education (EDN) has been restored with finite-time particle swarm optimization (FPSO) algorithm for advanced production and loading (APL) [8], [9]. The neural network was used to detect plant echo using the derivation of the root mean square system [10]. Using the support vector machine (SVM) and k nearest neighbour (KNN) algorithm a system was to find out about many diseases of $87.3 \%$ and $83.6 \%$ [11]. To enhance stability in single machine infinite bus (SMIB) used probabilistic signature scheme (PSS), genetic algorithm (GA) used to define parameters PSS [12]. Static var compensator (SVC) is used to set SMIB and matrix metalloproteinases (MMPS) parameters with the GA, we note that the network is unstable when not in use SVC [13]-[15]. To set parameters, use proportional integral derivative 
(PID) with PSO on the SMIB system and stability has been improved by SVC [16]-[18]. GA with DG apply to find out the optimal location on 33 bus and get rid of voltage drops and losses [19]. To determine the malicious type of communication, a genetic algorithm is proposed. This method can be applied in an intrusion detection system to identify the attack and enhance the security features of a computer network [20], [21]. GA was exercised to procure the values to improve heating, ventilation and air conditioning (HVAC) model [22]. GA was used to improve the parameters of the based Thyristor controlled series compensator (TCSC) controller to improve stability. The controller structures (LL and PID) used in the case of different disturbances and TCSC gave the best response [23], [24]. To enhance predicted mean vote (PMV) and find posterior probability density (PPD) value as input for energy value prediction thermal equation and smart algorithm used to control and boost the energy in heating, ventilation, and air conditioning (HVAC) by the rated and ideal air temperature inside, prevent the energy peaking [25], [26]. The teaching-learning-based optimization (TLBO) technology was used on a six-bus system, where the results showed a rapid damping to reach the stabilization state, and the parameters were set through proportional integral (PI) [27]. In this paper, a comparison was made between three types of flexible alternating current transmission system (FACT) devices, namely SVC, static synchronous compensator (STATCOM), and unified power flow controller (UPFC), and the best stability and damping enhancement of the system with UPFC [28].

The stability enhancement is based on PSS through TCSC control unit under turbulence. Real-coded genetic algorithm (RCGA) is used to obtain the parameters and singular value decomposition (SVD) damping control study is presented [29]-[31]. Flexible alternating current transmission systems have many types and are developed, including series, parallels, series-parallels, installed on SMIB [32]-[34].

Instability and system out of synchronization due to an error. Since the system is not able to return to its steady state, the error is eliminated. The change in angular velocity and oscillations does not make the system reach the transient stability state to out of synchronization. To enhance stability, compensate effort and enhance reactive and real capacity, it is necessary to improve the cost and compensate the transmission line. To obtain the optimum controller parameters, smart technologies that contribute to this purpose and boost the transient stability in electrical networks have been used. In this paper, the improvement that took place for network parameters in SMIB was done through the Matlab program and the application of the genetic algorithm, which helped the system to take out fluctuations and reach the stable states in speed deviation, variation of power angle and voltage deviation for 4\% step increase in mechanical torque input. Compared to other research in which many algorithms, FACTS and PSS. Have been applied to SMIB network to obtain system improvement and stability. The paper is split: section 2 explains the system, genetic algorithm in section 3 and section 4 discusses the results. Section 5 offer conclusion.

\section{POWER SYSTEM}

Figure 1 is a model of SMIB system and using MATLAB to develop the system [35]. To enhance the quality and stability, control is the most significant [36]. Through the parallel line the synchronous machine is fed to the infinite bus. $E_{t}$ terminal voltage and $E_{b}$ infinite bus voltage. $R_{e}$ and $X_{e}$ resistance and reactance of the transmission line respectively.

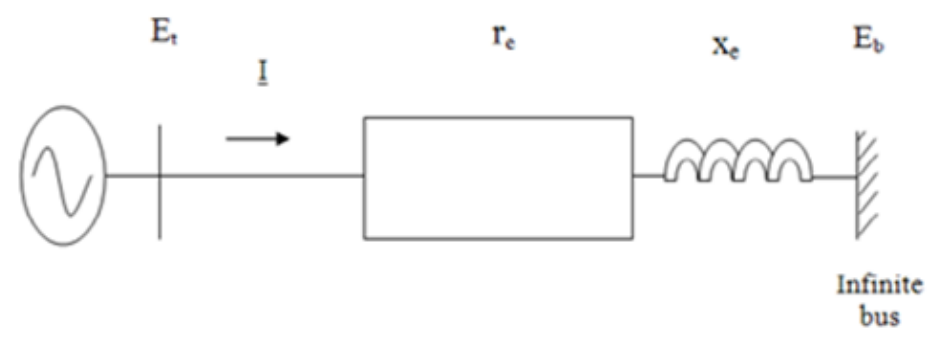

Figure 1. Single line diagram of SMIB system [23]

$$
\begin{aligned}
& \frac{d \delta}{d t}=\mathrm{wB}(\mathrm{Sm}-\mathrm{Smo}) \\
& \frac{d \delta_{m}}{d t}=\frac{1}{2 H}[-\mathrm{D}(\mathrm{Sm}-\mathrm{Smo})+\mathrm{Tm}-\mathrm{Te}] \\
& \frac{d E^{\prime} q}{d t}=\frac{1}{T^{\prime} d 0}\left[-E^{\prime}{ }_{q}+\left(X_{d}-X^{\prime}{ }_{d}\right) i_{d}+E_{f d}\right]
\end{aligned}
$$


$\frac{d E_{d}^{\prime}}{d t}=\frac{1}{T^{\prime} d 0}\left[-E_{d}^{\prime}+\left(X_{q}-X_{q}^{\prime}\right) i_{d q}\right]$

$T_{e}=E^{\prime}{ }_{d} i_{d}+E^{\prime}{ }_{q} i_{q}+\left(X^{\prime}{ }_{d}+X^{\prime}{ }_{q}\right) i_{d} i_{q}$

The equations for the stator and lattice are as follows,

$E_{q}^{\prime}+X^{\prime}{ }_{d} i_{d}=V_{q}$

$E^{\prime}{ }_{d}+X^{\prime}{ }_{q} i_{q}=V_{d}$

$V_{q}=-X_{e} i_{d}-E_{b} \cos \delta$

$V_{d}=X_{e} i_{q}-E_{b} \sin \delta$

the equations become,

$$
\begin{aligned}
& i_{d}=\frac{E_{b} \cos \delta-E_{q}^{\prime}}{X_{e}+X_{d}^{\prime}} \\
& i_{q}=\frac{E_{b} \sin \delta-E^{\prime}{ }_{d}}{X_{e}+X^{\prime}{ }_{q}}
\end{aligned}
$$

\section{METHOD}

This section describes the methods of modelling, formulation of the optimization problem, fitness function, load flow and implementation of the optimization algorithm for solving optimal problems. The network was linked with the genetic algorithm through the matrix laboratory (MATLAB) program by m-file, where the algorithm data was entered through programming and system simulation into MATLAB to minimizing voltage drop and power loss of the network. The fitness function can be calculated and the design of the function was a significant part of the entire optimization method for the modeling process. Voltage drop constraint calculated using (7) and (8) respectively.

The problems of reinforcement are used to solve many methods. In a specific time, we appreciate the existence of a suitable solution to the problem in the network, but there is no guarantee of obtaining the best solution [37]-[39]. GA used to control specific system parameters and solve problems. It contains many solutions that can be modified. There are many parents who are working to produce a new generation. GA is a research and optimization technique whose objective is to identify appropriate parameters by which results can be improved [40], [41]. Their candidate solutions are called chromosomes [12], [23], [42], [43]. By GA the parameters of the system controllers are optimized [44]. The expression of the individual uses his decency [23], [45]. GA easy and simple, so the researchers used it, and it has the ability to converge to reach the optimal solution [24], [46]-[49]. Figure 2 shows the flow chart of GA which works on generations.

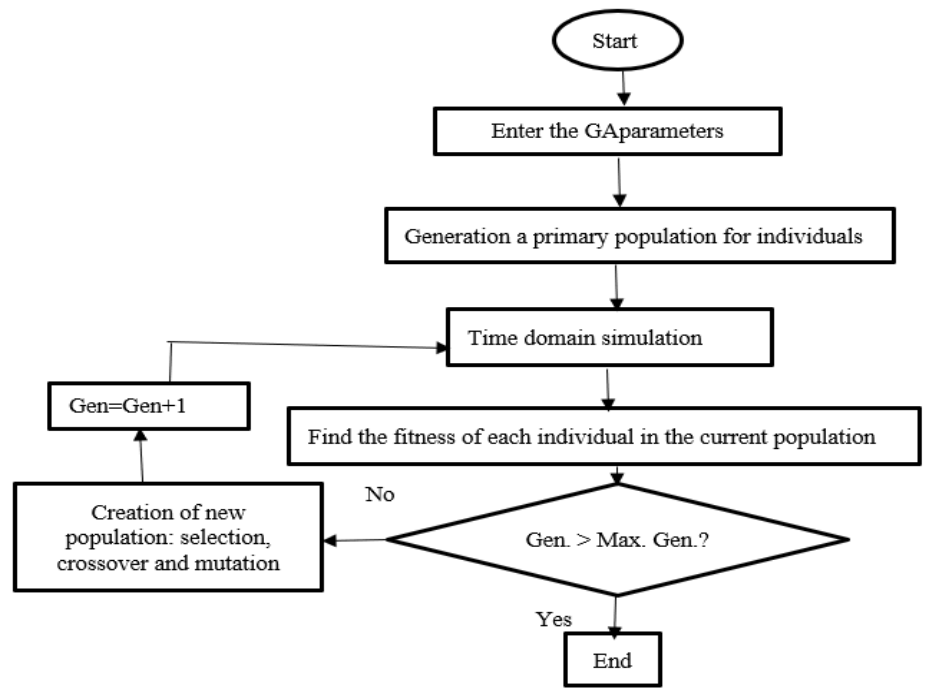

Figure 2. Flow chart of GA 
a) Fitness evaluates everyone.

b) The population is multiplied by repetition, and nomination of one of the fit is random, and individuals of higher fitness contribute better than less fit.

c) Mutation and crossover are factors for offspring.

d) The offspring is inserted and the operation is frequent.

\section{SIMULATION RESULTS}

In Figure 3 simulink for SMIB system using MATLAB. The simulink of subsystem is offer in Figure 4. The parameters for GA optimization routines can be found in [50]. The fault condition occurs at the middle of one line of $t_{c}=0.28 \mathrm{sec}$. To ensure user control was tested for three phase short circuits, we can observe that GA controller damps electromechanical oscillations as in Figure 5 offer the variation of the speed without controller and with GA, it shows are completely damped within $t_{c}=0.28$ sec. Figure 6 , the relative variation in the power angle of generator is cleared at the time clearing tc $=0.28 \mathrm{sec}$ when the response without GA and the responses with GA optimized, GA helps the system to be stable. The rotor angle swing decreases and the oscillation of dampen. Figure 7 offer the voltage at bus, Where we notice the suppression of oscillations with GA is better than a situation without GA. We note that the suppression of oscillations is better compared to the suppression in the case of using PSS with SMIB in the research [51], and this indicates the response of the network to the stable state thanks to the GA technique that helped to adjust the parameters. The results show the tunability and effectiveness of the modeling and that the proposal of the GA technique is distinguished by the damping of oscillations, low frequency, and the stability under severe turbulence to the steady-state operating condition. Hence, we find that the main objectives of this study are to reduce energy losses in the distribution system. Implementation of GA-based optimization by decreasing the velocity drift, power angle variation, and voltage drift by $4 \%$ showed a stepwise increase in the mechanical torque input. SMIB parameters are in Table 1.

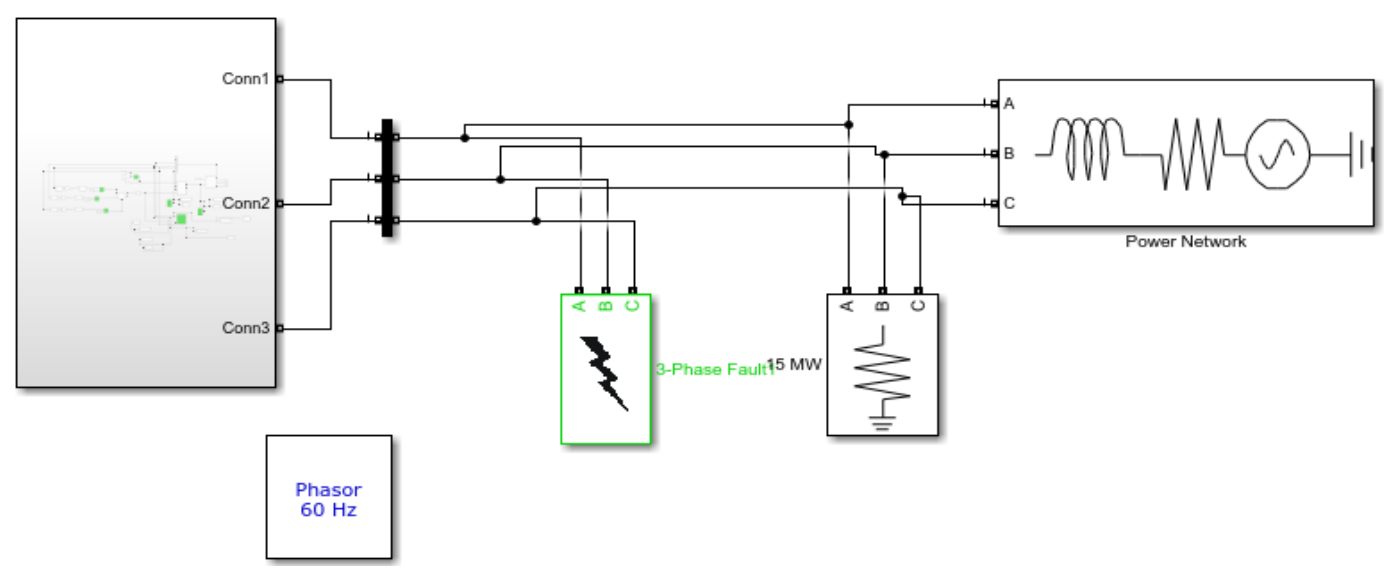

Figure 3. MATLAB simulink of SMIB

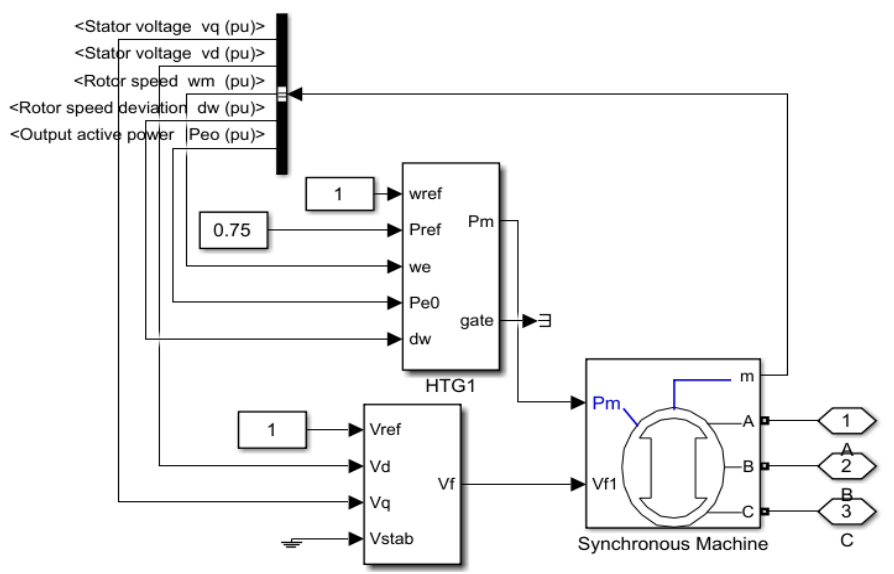

Figure 4. MATLAB simulink of subsystem 


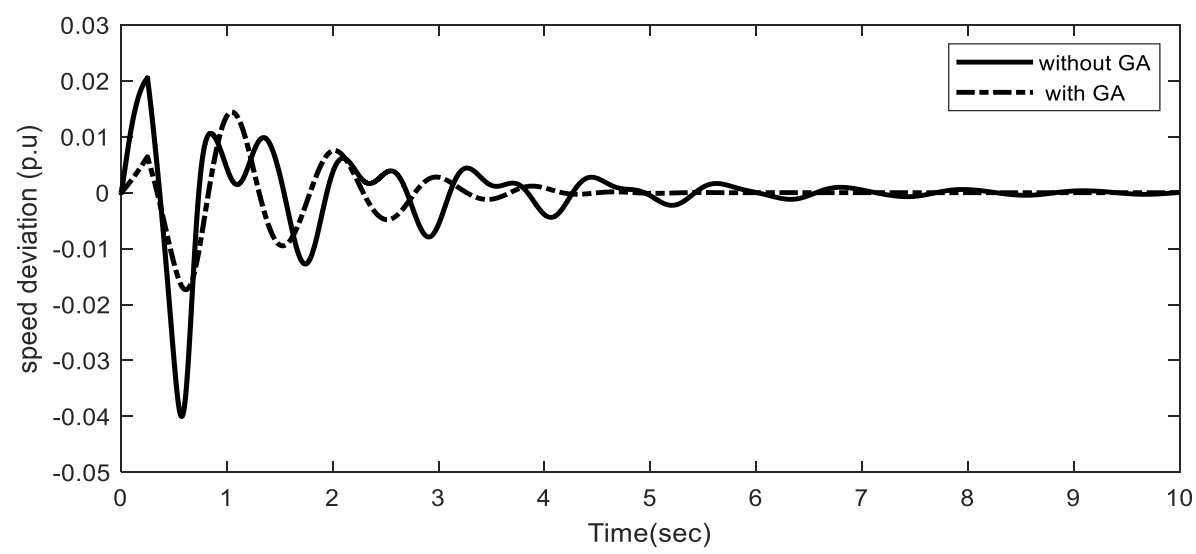

Figure 5. Speed deviation for $4 \%$ step increase in mechanical torque input

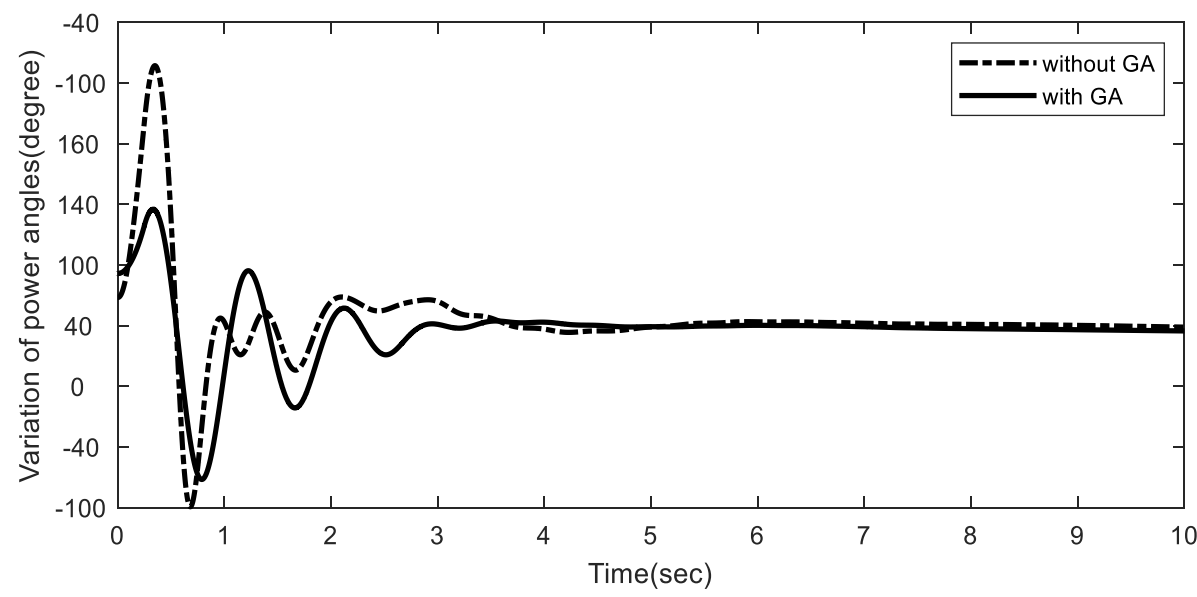

Figure 6. Variation of power angle for $4 \%$ step increase in mechanical torque input

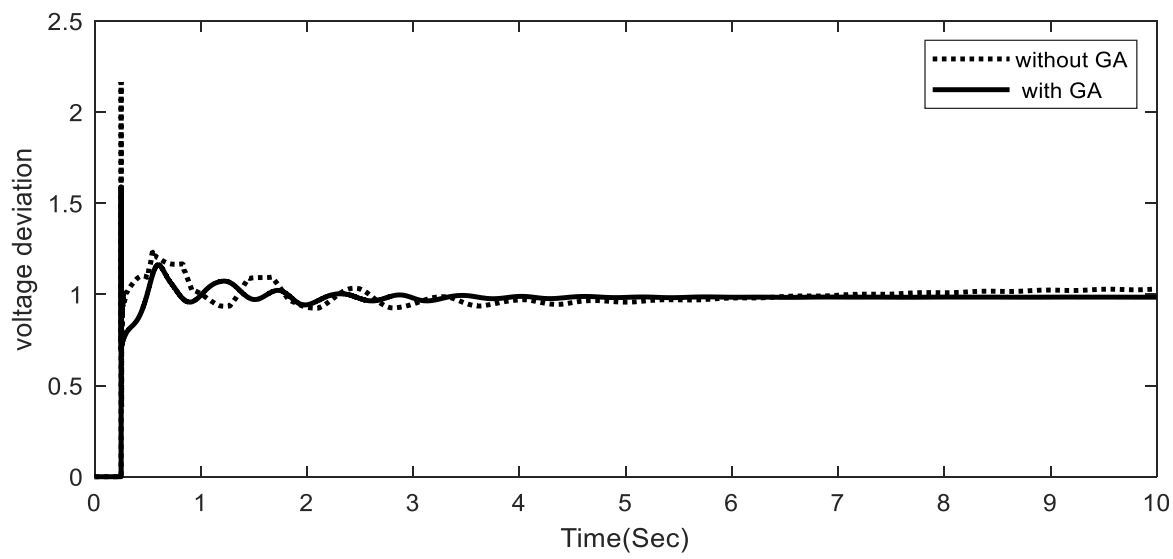

Figure 7. Voltage deviation for $4 \%$ step increase in mechanical torque input

Table 1. The parameters of SMIB

\begin{tabular}{|c|c|c|c|c|c|c|c|c|c|c|c|c|c|}
\hline $\begin{array}{l}V_{\text {inf }} \\
\text { (p.u) }\end{array}$ & $\begin{array}{l}\mathrm{H} \\
(\mathrm{s})\end{array}$ & D & $V_{t}($ p.u $)$ & $K_{A}$ & $\begin{array}{c}R_{S} \\
\text { (p.u) }\end{array}$ & $\begin{array}{c}R_{e} \\
\text { (p.u) }\end{array}$ & $T_{d}(\mathrm{~s})$ & $T_{A}(\mathrm{~s})$ & $\begin{array}{c}w_{s}(\mathrm{ra} \\
\mathrm{d} / \mathrm{s})\end{array}$ & $\begin{array}{c}X_{d} \\
\text { (p.u) }\end{array}$ & $X_{q}(\mathrm{p} . \mathrm{u})$ & $X_{e}(\mathrm{p} . \mathrm{u})$ & $X_{d}^{\prime}{ }^{\prime}$ (p.u) \\
\hline $1 \angle 0^{\circ}$ & 2.52 & 0 & $1.72 \angle 19.3$ & 400 & 0.0 & 0.2 & 5.9 & 0.2 & 314 & 1.7 & 1.64 & 0.7 & 0.245 \\
\hline
\end{tabular}




\section{CONCLUSION}

Power system behaviors are observed to compensate for low oscillations and the stability performance is improved by effective moisture oscillation from low frequency. The results show this proposed model is suitable for accurately and effectively analyzing the stability as network-based GA by enhancing the transient stability of SMIB. The simulation described here was performed using GA. It was a training of the genetic algorithm, with the SMIB pre-error condition used as a typical reference for the control unit, it could be concluded that the system increase in the critical clearing time and damping of the electromechanical power oscillations. Flexible AC transmission systems can be applied with the genetic algorithm in this network, and this is the direction of research to complete smart calculations.

\section{ACKNOWLEDGEMENTS}

The authors are grateful to the Babylon technical institute and technical college Al-Mussaib, AlFurat Al-Awsat technical university, Iraq for support.

\section{REFERENCES}

[1] K. Padiyar, "Power system dynamics: stability \& control," BS publications, 2010.

[2] E. E. T. O. Committee, I. P. Group, E. E. P. Group, and I. P. E. Society, IEEE Transactions on Power Apparatus and Systems, vol. 95: IEEE, 1976

[3] Z. H. Al-Tameemi, H. H. Enawi, K. M. Al-Anbary, D. H. Al-Mamoori, and H. M. Almukhtar, "An objective study of behavior of permanent magnet synchronous motor under abnormal conditions," International Journal of Engineering \& Technology, vol. 7, pp. 1970-1976, 2018, doi: 10.14419/ijet.v7i4.15550.

[4] U. Khaled, A. M. Eltamaly, and A. Beroual, "Optimal power flow using particle swarm optimization of renewable hybrid distributed generation," Energies, vol. 10, 2017, p. 1013, doi: 10.3390/en10071013

[5] M. Rosselan, S. I. Sulaiman, and I. Musirin, "Sizing optimization of large-scale grid-connected photovoltaic system using cuckoo search," Indonesian Journal of Electrical Engineering and Computer Science (IJEECS), vol. 8, pp. 169-176, 2017, doi: 10.11591/ijeecs.v8.i1.pp169-176.

[6] Z. A. Kamaruzzaman, A. Mohamed, and R. Mohamed, "Optimal placement of grid-connected photovoltaic generators in a power system for voltage stability enhancement," Indonesian Journal of Electrical Engineering and Computer Science (IJEECS), vol. 13, pp. 339-346, 2019, doi: 10.11591/ijeecs.v13.i1.pp339-346.

[7] H. Chappa and T. Thakur, "Voltage instability detection using synchrophasor measurements: A review," International Transactions on Electrical Energy Systems, vol. 30, p. e12343, 2020, doi: 10.1002/2050-7038.12343.

[8] E. Karunarathne, J. Pasupuleti, J. Ekanayake, and D. Almeida, "Network loss reduction and voltage improvement by optimal placement and sizing of distributed generators with active and reactive power injection using fine-tuned pso," Indonesian Journal of Electrical Engineering and Computer Science (IJEECS), vol. 21, pp. 647-656, 2021, doi: 10.11591/ijeecs.v21.i2.pp647-656.

[9] E. Karunarathne, J. Pasupuleti, J. Ekanayake, and D. Almeida, "Comprehensive learning particle swarm optimization for sizing and placement of distributed generation for network loss reduction," Indonesian Journal of Electrical Engineering and Computer Science (IJEECS), vol. 20, pp. 16-23, 2020, doi: 10.11591/ijeecs.v20.i1.pp16-23.

[10] M. F. Mavi, Z. Husin, R. B. Ahmad, Y. M. Yacob, R. Farook, and W. K. Tan, "Mango ripeness classification system using hybrid technique," Indonesian Journal of Electrical Engineering and Computer Science (IJEECS), vol. 14, pp. 859-868, 2019, doi: 10.11591/ijeecs.v20.i1.pp16-23.

[11] S. B. Jadhav, V. R. Udup, and S. B. Patil, "Soybean leaf disease detection and severity measurement using multiclass SVM and KNN classifier," International Journal of Electrical and Computer Engineering, vol. 9, p. 4092, 2019, doi: 10.11591/ijece.v9i5.pp4077-4091.

[12] S. Keskes, N. Bouchiba, S. Sallem, L. C.-Alaoui, and M. Kammoun, "Optimal tuning of power system stabilizer using genetic algorithm to improve power system stability," in 2017 International Conference on Green Energy Conversion Systems (GECS), 2017, pp. 1-5, doi: 10.1109/GECS.2017.8066200.

[13] S. Hameed and P. Garg, "Improvement of power system stability using genetically optimized SVC controller," International Journal of System Assurance Engineering and Management, vol. 5, pp. 475-486, 2014, doi: 10.1007/s13198-014-0233-6.

[14] J. MirarabRazi, I. H. Navrodi, I. Ghajar, and M. Salahi, "Identifying optimal location of ecotourism sites by analytic network process and genetic algorithm (GA):(Kheyroud Forest)," International Journal of Environmental Science and Technology, vol. 17, pp. 2583-2592, 2020, doi: 10.1007/s13762-020-02633-z.

[15] Z. H. Al-Tameemi, O. M. Neda, F. A. Jumaa, D. H. Al-Mamoori, M. H. Aljanabi, and J. M. Jasim, "Optimal Sizing and Location of DG Units for Enhancing Voltage Profile and Minimizing Real Power Losses in the Radial Power Systems Based on PSO Technique," in IOP Conference Series: Materials Science and Engineering, 2019, p. 042021, doi: 10.1088/1757-899X/518/4/042021.

[16] A. D. Falehi, "Optimal robust disturbance observer based sliding mode controller using multi-objective grasshopper optimization algorithm to enhance power system stability," Journal of Ambient Intelligence and Humanized Computing, vol. 11, pp. 5045-5063, 2020, doi: 10.1007/s12652-020-01811-8.

[17] S. Mohd Nasir et al., "Multistage artificial immune system for static VAR compensator planning," 2019, doi: 10.11591/ijeecs.v14.i1.pp346-352.

[18] N. Kamari, I. Musirin, Z. Hamid, and A. Ibrahim, "Optimal tuning of SVC-PI controller using whale optimization algorithm for angle stability improvement," Indones J Electr Eng Comput Sci, vol. 12, pp. 612-619, 2018, doi: 10.11591/ijeecs.v12.i2.pp612-619.

[19] A. Musa and T. Tengku Hashim, "Optimal sizing and location of multiple distributed generation for power loss minimization using genetic algorithm," 2019, doi: 10.11591/ijeecs.v16.i2.pp956-963.

[20] H. Suhaimi, S. I. Suliman, I. Musirin, A. F. Harun, and R. Mohamad, "Network intrusion detection system by using genetic algorithm," Indonesian Journal of Electrical Engineering and Computer Science (IJEECS), vol. 16, p. 1593, 2019, doi: 10.11591/ijeecs.v16.i3.pp1593-1599. 
[21] D. S. Kim, H.-N. Nguyen, and J. S. Park, "Genetic algorithm to improve SVM based network intrusion detection system," in 19th International Conference on Advanced Information Networking and Applications (AINA'05), vol. 1, 2005, pp. 155-158, doi: 10.1109/AINA.2005.191.

[22] S. A. Mohammed, O. A. Awad, and A. M. Radhi, "Optimization of energy consumption and thermal comfort for intelligent building management system using genetic algorithm," Indonesian Journal of Electrical Engineering and Computer Science (IJEECS), vol. 20, pp. 1613-1625, 2020, doi: 10.11591/ijeecs.v20.i3.pp1613-1625.

[23] S. Panda and N. P. Padhy, "MATLAB/SIMULINK based model of single-machine infinite-bus with TCSC for stability studies and tuning employing GA," International Journal of Computer Science And Engineering, vol. 1, no. 1, pp. 50-59, 2007.

[24] J. Ra'afat, "Enhancement of Transient Stability for Iraqi Power System by using Fuzzy-Genetic Controller," Master Thesis, University of Technology, Baghdad, Iraq, 2007.

[25] W. Tariq, M. L. Othman, N. I. A. Wahab, and M. Ebrahim, "A Review on ESCO's Challenges and Project Management as a solving tool," Indonesian Journal of Electrical Engineering and Computer Science (IJEECS), vol. 12, pp. 269-274, 2018, doi: 10.11591/ijeecs.v12.i1.pp269-274.

[26] T. S. Gunawan et al., "Prototype design of smart home system using internet of things," Indonesian Journal of Electrical Engineering and Computer Science (IJEECS), vol. 7, pp. 107-115, 2017, doi: 10.11591/ijeecs.v7.i1.pp107-115.

[27] Z. S. Hasan and M. N. Hawas, "Using Teaching Learning Based Optimization to Efficacious and Tuning of UPFC-PODs of Interconnected Systems," in IOP Conference Series: Materials Science and Engineering, 2020, p. 012001, doi: 10.1088/1757899X/745/1/012001.

[28] Z. S. Hasan and M. N. Hawas, "Enhancement of Power System Transent Stability of A multimachine Based on Interactions of PSS with Facts Devices," Journal of Mechanical Engineering Research and Developments, vol. 42, pp. 161-167, 2019, doi: 10.26480/jmerd.04.2019.161.167.

[29] A. T. Al-Awami, Y. A.-Magid, and M. Abido, "A particle-swarm-based approach of power system stability enhancement with unified power flow controller," International Journal of Electrical Power \& Energy Systems, vol. 29, pp. 251-259, 2007, doi: 10.1016/j.ijepes.2006.07.006.

[30] D. H. Al-Mamoori, M. H. Aljanabi, O. M. Neda, Z. H. Al-Tameemi, and A. A. Alobaidi, "Evaluation of gas fuel and biofuel usage in turbine," Indonesian Journal of Electrical Engineering and Computer Science (IJEECS), vol. 14, pp. 1097-1104, 2019, doi: 10.11591/ijeecs.v14.i3.pp1097-1104.

[31] T. T. Azeez and A. A. Abdelfattah, "Transient Stability Enhancement and Critical Clearing Time Improvement for Kurdistan Region Network using Fact Configuration," Journal of Engineering, vol. 26, pp. 50-65, 2020, doi: 10.31026/j.eng.2020.10.04.

[32] H. F. Wang, "Multi-agent co-ordination for the secondary voltage control in power-system contingencies," IEE ProceedingsGeneration, Transmission and Distribution, vol. 148, 2001, pp. 61-66, doi: 10.1049/ip-gtd:20010025.

[33] H. Wang and W. Keerthipala, "Fuzzy-neuro approach to fault classification for transmission line protection," IEEE Transactions on Power Delivery, vol. 13, pp. 1093-1104, 1998, doi: 10.1109/61.714467.

[34] H. M. Almukhtar, Z. H. Al-Tameemi, K. M. Al-Anbary, M. K. Abbas, H. Hung-Yao, and D. H. Al-Mamoori, "Feasibility Study of Achieving Reliable Electricity Supply Using Hybrid Power System for Rural Primary Schools in Iraq: A Case Study with Umm Qasr Primary School," International Journal of Electrical and Computer Engineering, vol. 9, p. 2822, 2019, doi: 10.11591/ijece.v9i4.pp2822-2830.

[35] G. S. Ghfarokhi, M. Arezoomand, and H. Mahmoodian, "Analysis and simulation of the single-machine infinite-bus with power system stabilizer and parameters variation effects," in 2007 International Conference on Intelligent and Advanced Systems, 2007, pp. 167-171, doi: 10.1109/ICIAS.2007.4658368.

[36] M. J. Gibbard, P. Pourbeik, and D. J. Vowles, Small-signal stability, control and dynamic performance of power systems, University of Adelaide press, 2015, doi: 10.20851/small-signal.

[37] S. Gerbex, R. Cherkaoui, and A. J. Germond, "Optimal location of multi-type facts devices in a power system by means of genetic algorithms," IEEE transactions on power systems, vol. 16, pp. 537-544, 2001, doi: 10.1109/59.932292.

[38] D. E. Goldberg, "Genetic algorithms in search, optimization, and machine learning. Addison," Reading, 1989.

[39] L.-J. Cai and I. Erlich, "Simultaneous coordinated tuning of PSS and FACTS damping controllers in large power systems," IEEE Transactions on power systems, vol. 20, pp. 294-300, 2005, doi: 10.1109/TPWRS.2004.841177.

[40] H. Pandey, "Is Parameters Quantification in Genetic Algorithm Important, How to do it?," IAES International Journal of Artificial Intelligence (IJ-AI), vol. 6, pp. 112-123, 2017, doi: 10.11591/ijai.v6.i3.pp112-123.

[41] K. Kamil, K. Chong, H. Hashim, and S. Shaaya, "A multiple mitosis genetic algorithm," 2019, doi: 103.227.140.9/handle/123456789/13219.

[42] M. Shafiullah, M. J. Rana, M. S. Alam, and M. Abido, "Online tuning of power system stabilizer employing genetic programming for stability enhancement," Journal of Electrical Systems and Information Technology, vol. 5, pp. 287-299, 2018, doi: 10.1016/j.jesit.2018.03.007.

[43] K. Sebaa and M. Boudour, "Optimal locations and tuning of robust power system stabilizer using genetic algorithms," Electric Power Systems Research, vol. 79, pp. 406-416, 2009, doi: 10.1016/j.epsr.2008.08.005.

[44] S. Panda and N. Padhy, "Thyristor controlled series compensator-based controller design employing genetic algorithm: a comparative study," International Journal of Electronics, Circuits and Systems, vol. 1, pp. 38-47, 2007, doi: 10.1.1.359.9573.

[45] P. G. Burade and J. Helonde, "By using Genetic Algorithm Method for Optimal Location of Facts Devices in the Deregulated Power System," Journal of Theoretical \& Applied Information Technology, vol. 17, 2010, doi: 10.1.1.299.5505.

[46] H. Wang, "A unified model for the analysis of FACTS devices in damping power system oscillations. III. Unified power flow controller," IEEE Transactions on Power Delivery, vol. 15, pp. 978-983, 2000, doi: 10.1109/61.871362.

[47] H. Shayeghi, H. Shayanfar, S. Jalilzadeh, and A. Safari, "A PSO based unified power flow controller for damping of power system oscillations," Energy conversion and management, vol. 50, pp. 2583-2592, 2009, doi: 10.1016/j.enconman.2009.06.009.

[48] F. Salata, V. Ciancio, J. Dell'Olmo, I. Golasi, O. Palusci, and M. Coppi, "Effects of Local Conditions on the Multi-Variable and Multi-Objective Energy Optimization of Residential Buildings Using Genetic Algorithms," Applied Energy, vol. 260, p. 114289, 2020, doi: 10.1016/j.apenergy.2019.114289.

[49] H. Wang and F. Swift, "A unified model for the analysis of FACTS devices in damping power system oscillations. I. Singlemachine infinite-bus power systems," IEEE Transactions on Power Delivery, vol. 12, pp. 941-946, 1997, doi: 10.1109/61.584417.

[50] C. Houck, J. Joines, and M. Kay, "A genetic algorithm for function optimization: A MTLAM implementation. NCSU-IE," in Technical Report, 95-09, ed: North Caroline State University, 1995.

[51] V. Desai, "Transient Stability Enhancement of SMIB using AVR and PSS," International Journal of Engineering Research and Development (IJERD), vol. 6, no. 1, pp. 1-12, 2016, doi: 10.1177/2053951718820549. 


\section{BIOGRAPHIES OF AUTHORS}
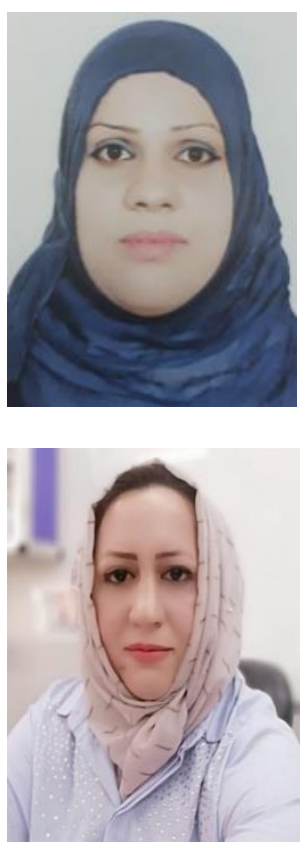

Zinah Salah Hasan (iD SC P is an assistant teacher at Babylon Technical Institute, Al Furat Al Awsat Technical University, Iraq. She holds a master's degree in electrical power engineeringFrom the College of Electrical Engineering Technical University of Baghdad. She holds a bachelor's degree from the Mussaib Technical College, Al-Furat Al- Awsat Technical University. Her research journals are in Electrical Power, High Voltage, Power System Algorithms, and Electrical Analytics, with $1 \mathrm{H}$-index. She worked as a teacher in the Department of Electronic Technology and the Department of Power Mechanics at Babylon Technical Institute, Al Furat Al Awsat Technical University. Her interests include many researches in electrical power and flexible alternating currents systems, renewable energy technology and power electronics. She can be contacted at email: zinah.hasan@ atu.edu.iq.

Dalya H. Al-Mamoori (iD SC SC $\mathrm{S}$ is a teacher at Department of Electrical Power Engineering, Technical College Al-Mussaib, Al-Furat Al- Awsat Technical University, Babil, Iraq. She received the B.Sc. degree in Electrical Power Engineering from Technical College Al-Mussaib, Al-Furat Al- Awsat Technical University and the M.Sc. degree in Electrical Power Engineering from the University Tenaga Nasional, Malaysia. Her research areas are Power Electronics, Renewable Energy Technology, High Voltage, Power System, Biofuel, Micro-gas turbine, Thermal Stability, Synchronous Motor, Algorithms, and Electrical Analytics, with $3 \mathrm{H}$-index. She is currently a teacher with the Department of Electrical Power Engineering, Technical College Al-Mussaib, Al-Furat Al- Awsat Technical University. Her research interest's renewable energy technology, power electronics and microgrids cluster. She can be contacted at email: daliahamza784@atu.edu.iq. 